\title{
Nível crítico de toxidez do ácido acético em culturas alternativas para solos de várzea
}

\author{
Acetic acid critical level in alternative crops for wetland soils
}

\author{
Fabiana Schmidtt ${ }^{\mathrm{I}}$ Magali de Ávila Fortes ${ }^{\mathrm{I}}$ Leandro Bortolon ${ }^{\mathrm{II}}$ \\ Elisandra Solange Oliveira Bortolon ${ }^{\mathrm{II}}$ Rogério Oliveira de Sousa ${ }^{\mathrm{I}^{*}}$
}

\section{RESUMO}

A deficiente drenagem natural dos solos de várzea proporciona um ambiente anaeróbico, favorecendo a formação de substâncias tóxicas, como o ácido acético, que afeta o desempenho de espécies de sequeiro nesses ecossistemas. O presente estudo foi conduzido com os objetivos de avaliar os efeitos e estabelecer os níveis críticos de toxidez do ácido acético para culturas de sequeiro alternativas para solos de várzea, como o milho, a soja e o sorgo. Os tratamentos constaram de seis doses de ácido acético, entre zero e $8 \mathrm{mM}$, para milho (Embrapa BRS 1001) e sorgo (BRS 307), e quatro doses entre zero e $4 \mathrm{mM}$, para soja (Embrapa BRS 133), com seis repetições, em delineamento completamente casualizado. Os indicadores avaliados foram os parâmetros morfológicos do sistema radicular (comprimento, raio, área e massa seca relativas) e concentração de $N, P, K$, Ca e Mg e massa seca relativa da parte aérea das plantas. O ácido acético foi tóxico para as culturas do milho, da soja e do sorgo, causando reduções no comprimento, na área e na massa seca radicular e na massa seca e na concentração de $N, P, K, C a$ e Mg da parte aérea. As concentrações de ácido acético responsáveis pela inibição de $50 \%$ do comprimento radicular relativo foram de $2 \mathrm{mM}$ para a soja e 2,7mM para o milho e o sorgo.

Palavras-chave: ácidos orgânicos, terras baixas, culturas de sequeiro.

\section{ABSTRACT}

The poor drainage of wetland soils originates an anaerobic environment favoring the appearance of toxic substances, like acetic acid, which affects negatively the growth of dryland crops. The present work was carried out with the objective of evaluating the effects of acetic acid and establishing its threshold for alternative crops cultivated in wetland soils, such as maize, soybean and sorghum. Plants of maize

\begin{abstract}
(Embrapa BRS 1001) and sorghum (BRS 307) were exposed to six acetic acid levels, from zero to $8 \mathrm{mM}$; whereas plants of soybean (Embrapa BRS 133) were exposed to four levels, from zero to $4 \mathrm{mM}$. The experimental design used was completely randomized with six replications. Morphological parameters of plant root system (length, root radium, area and relative dry mass), relative shoot dry mass and $N, P, K, C a$ and $M g$ concentration in plant shoot were assessed. The acetic acid was toxic to maize, soybean and sorghum, being evidenced by decreases in the root length and dry mass, in the total plant dry mass and in the $\mathrm{N}, \mathrm{P}, \mathrm{K}, \mathrm{Ca}$ and $\mathrm{Mg}$ contents in the plant shoot. The acetic acid concentrations responsible for decreasing $50 \%$ of the relative root length were $2 \mathrm{mM}$ for soybean and $2.7 \mathrm{mM}$ for maize and sorghum.
\end{abstract}

Key words: organic acids, lowlands, dryland crops.

\section{INTRODUÇÃO}

A região Sul do Brasil apresenta uma área de 6,8 milhões de hectares constituída por solos de várzea, representando $20 \%$ da área total do Estado do Rio Grande do Sul (PINTO, et al., 2004). Uma das principais atividades econômicas conduzidas nessas áreas tem sido o binômio arroz irrigado-pecuária de corte extensiva. Entretanto, a partir do início dos anos 90, surgiram sistemas alternativos, como o plantio direto e a rotação de culturas com o arroz irrigado, envolvendo espécies de sequeiro como o milho, a soja e o sorgo.

O principal fator que restringe o crescimento de espécies no ecossistema de várzeas é a deficiente

IDepartamento de Solos, Universidade Federal de Pelotas (UFPEL), CP 354, Campus Universitário s/n, 96010-900, Capão do Leão, RS, Brasil. E-mail: rogerio.sousa@pq.cnpq.br. *Autor para correspondência.

IIUniversidade Federal do Rio Grande do Sul (UFRGS), Porto Alegre, RS, Brasil. 
drenagem natural dos solos, que, mesmo em cultivos de sequeiro, provoca condições para um ambiente anaeróbico, favorecendo a formação de substâncias tóxicas. A decomposição anaeróbica de resíduos vegetais favorece a formação de uma série de produtos intermediários resultantes principalmente da fermentação, entre os quais, se destacam os ácidos orgânicos alifáticos de cadeia curta e de baixo peso molecular, como o acético, o propiônico e o butírico, que ocorrem, geralmente, na faixa de concentração de 0,1 a 14mM (CAMARGO et al., 2001; SOUSA et al., 2002) e na proporção de 6:3:1, respectivamente (BOHNEN et al., 2005). Segundo SOUSA \& BORTOLON (2002), esses ácidos atingem valor máximo poucos dias após o alagamento, podendo causar toxidez às plantas.

O efeito tóxico desses ácidos depende do tipo e da concentração (RAO \& MIKKELSEN, 1977). A fitotoxidez dos ácidos orgânicos aumenta na ordem acético, propiônico e butírico, ou seja, quanto maior o tamanho da cadeia de carbonos do ácido, mais tóxico ele é (TAKIJIMA, 1964; RAO \& MIKKELSEN, 1977; KROGMEIER \& BREMNER, 1990). Porém, desses três ácidos, o acético é produzido em maior quantidade, podendo representar mais de $60 \%$ do total dos ácidos orgânicos produzidos (SOUSA \& BORTOLON, 2002).

A fitotoxidez de ácidos orgânicos, como o ácido acético, decorre da diminuição da respiração e fosforilação oxidativa das raízes, diminuindo a absorção de nutrientes (TAKENAGA, 1995). Além disso, os ácidos afetam processos fisiológicos importantes, como aeração interna, transporte vascular e respiração, e comprometem a integridade das membranas celulares (ARMSTRONG \&ARMSTRONG, 2001).

A quantificação dos efeitos dos ácidos orgânicos sobre as plantas cultivadas em solo é dificultada por vários fatores, como a deficiência de oxigênio, liberação de compostos tóxicos diretamente dos resíduos, formação de compostos fenólicos tóxicos e ocorrência de patógenos causadores de doenças radiculares (SOUSA et al., 2002). Assim, experimentos em solução nutritiva possibilitam separar e caracterizar os efeitos dos ácidos orgânicos nas plantas.

Um dos aspectos que merece mais estudos diz respeito aos níveis críticos de toxidez dos ácidos orgânicos às culturas. Segundo JONES \& JONES (1992), em estudos de tolerância a fatores abióticos, como a fitotoxidez por ácido acético, é desejável que sejam estabelecidas faixas de concentração que promovam reduções entre 30 e 60\% nas diferentes variáveis de resposta. Quando são utilizadas doses muito altas, o dano às plantas pode ser muito intenso e não permitir que sejam observadas diferenças de reação à toxidez entre as espécies.
Os níveis críticos do ácido acético reportados na literatura são bastante variáveis e normalmente foram determinados em genótipos de arroz. Assim, este estudo teve por objetivos avaliar os efeitos do ácido acético nos parâmetros morfológicos radiculares, na massa seca e na concentração de nutrientes da parte aérea e estabelecer os níveis críticos de toxidez em culturas de sequeiro alternativas para solos de várzea, como o milho, a soja e o sorgo.

\section{MATERIAL E MÉTODOS}

Para atingir os objetivos propostos, foram realizados três experimentos, em solução nutritiva, em bancada de laboratório com fornecimento de luz artificial, sendo utilizados como unidades experimentais tubos de ensaio com volume de $100 \mathrm{~mL}$. Os tratamentos testados foram concentrações de ácido acético: 0,0; 1,0; 2,0; 4,0; 6,0; 8,0mM, para milho (Embrapa BRS 1001) e sorgo (BRS 307) (Experimentos 1 e 2), e 0,0; 1,0; 2,0; 4,0mM, para soja (Embrapa BRS 133) (Experimento 3), com seis repetições em delineamento experimental inteiramente casualizado.

As sementes foram pré-germinadas em papel de germinação, em forma de rolos parcialmente mergulhados em vasilha plástica com água destilada, para que se mantivessem úmidos. Após a germinação, foram selecionadas as plântulas mais uniformes para serem transferidas para os tubos de ensaio. Os tubos de ensaio foram preenchidos com $90 \mathrm{~mL}$ de solução nutritiva completa e quantidades crescentes de ácido acético, de modo que a concentração final do ácido correspondesse aos diferentes tratamentos testados. A solução nutritiva apresentou a seguinte composição: 4,0mM L-1 de $\mathrm{N}$; $1,5 \mathrm{mM} \mathrm{L}^{-1}$ de Ca; $1,2 \mathrm{mM} \mathrm{L}^{-1}$ de K; 1,2mM L $\mathrm{m}^{-1}$ de $\mathrm{P} ; 1,0 \mathrm{mM} \mathrm{L}^{-1}$ de Cl; $1,25 \mathrm{mM} \mathrm{L}^{-1}$ de $\mathrm{Mg}^{-1}$ 1,26mM L ${ }^{-1}$ de $S ; 0,0091 \mathrm{mM} \mathrm{L}^{-1}$ de $\mathrm{Mn} ; 0,0001 \mathrm{mM} \mathrm{L}^{-1}$ de Mo; 0,0231mM L-1 de B; 0,079mM L-1 de $\mathrm{Cu}$; 0,090mM L-1 de Fe e 0,0015mM L-1 de Zn. O pH da solução nutritiva foi ajustado ao valor 4,7 , utilizandose $\mathrm{HCl}$ 0,5mol L ${ }^{-1}$ ou $\mathrm{NaOH} 1,0 \mathrm{~mol} \mathrm{~L}^{-1}$. O valor de $\mathrm{pH}$ foi estabelecido com base no logaritmo da constante de dissociação (pK) do ácido acético, que é 4,7 (LYNCH, 1986).

As plântulas foram colocadas em disco de isopor para que se mantivessem na superfície da solução nutritiva. Foi instalado um sistema de aeração da solução nutritiva de onde derivavam diversas mangueiras, uma para cada um dos tubos de ensaio. A solução nutritiva foi renovada a cada três dias. As plantas de milho e de sorgo permaneceram 10 dias na solução nutritiva sob efeito dos tratamentos e as de soja oito dias, sendo colhidas após esses períodos. 
Após a coleta do material, realizou-se a separação da parte aérea e das raízes. Na parte aérea, após secagem até massa constante em estufa com circulação de ar a $65^{\circ} \mathrm{C}$, foram determinadas a massa seca da parte aérea e a concentração de nutrientes (TEDESCO et al., 1995).

As raízes foram mantidas em refrigeração até a determinação dos atributos morfológicos do sistema radicular (TENNANT, 1975). O comprimento (L) foi estimado pelo método de interseção de quadrículas, o raio (r) foi calculado por $\mathrm{r}=$ (peso úmido/ $\pi . L) 1 / 2$, a área radicular (AR) foi calculada a partir da fórmula $A R=2 . \pi$.r.L e a massa seca radicular foi quantificada em balança de precisão, após a secagem em estufa, a $65^{\circ} \mathrm{C}$. Os atributos morfológicos foram expressos em quantidades relativas, tomando como referência os valores obtidos na testemunha sem ácido acético.

As variáveis estudadas foram analisadas estatisticamente por meio do emprego do programa Statistical Analysis System (SAS, 2004). Os dados foram submetidos à análise de variância e, havendo significância para o teste $\mathrm{F}$, realizou-se o estudo do efeito das concentrações de ácido acético nos parâmetros avaliados para o milho, a soja e o sorgo, por meio de regressões polinomiais de primeiro e segundo graus, utilizando o comando GLM.

\section{RESULTADOS E DISCUSSÃO}

A análise de regressão foi significativa para os efeitos das doses de ácido acético sobre os parâmetros morfológicos radiculares das plântulas de milho, soja e sorgo (Figura 1). O comprimento e a área radicular das três culturas, a massa seca radicular da soja e do sorgo e o raio radicular do sorgo diminuíram sensivelmente com o aumento das doses de ácido acético (Figura 1a, 1b, 1c e 1d). As variáveis comprimento e área radicular foram as que apresentaram as maiores reduções relativas frente aos tratamentos, com reduções médias de até $90 \%$ para milho e sorgo e aproximadamente $70 \%$ para a soja, na dose mais elevada de ácido acético testada, 8,0 e 4,0mM, respectivamente. A variável massa seca radicular apresentou reduções relativas médias menores, não diferindo significativamente entre doses para o milho e reduzindo 29\% para a soja na dose mais elevada de ácido acético, 4,0mM. No entanto, o sorgo teve uma redução relativa de $67 \%$ na massa seca radicular, na dose de $8,0 \mathrm{mM}$ de ácido acético, evidenciando respostas diferenciais entre culturas em relação aos tratamentos.

O menor crescimento radicular ocorreu provavelmente porque o ácido acético afeta a integridade da membrana plasmática, causando o efluxo de íons inorgânicos e material orgânico para o meio externo (LEE, 1977), e interfere em processos de produção de energia na planta, como fosforilação oxidativa e respiração (TAKENAGA, 1995). JACKSON \& JOHN (1980) observaram que os ácidos orgânicos acético, propiônico e fórmico, na forma não dissociada, promovem um aumento da proporção dos ácidos graxos saturados, como os ácidos palmítico, esteárico e oleico, e diminuição da proporção dos insaturados, como os ácidos linoleico e linolênico, o que aumentou a permeabilidade da membrana aos íons.

Os efeitos fisiológicos da toxidez pelos ácidos orgânicos estão relacionados com a inibição da divisão celular do sistema radicular que está diretamente em contato com os ácidos, sendo esta a provável razão principal para o menor crescimento radicular (ARMSTRONG \& ARMSTRONG, 2001). Aeração interna, transporte vascular, fotossíntese e respiração, além da degradação das membranas celulares e consequente perda do conteúdo celular para o meio, são, também, processos fisiológicos afetados pelos ácidos orgânicos (ARMSTRONG \& ARMSTRONG, 2001). Vários estudos (SOUSA \& BORTOLON, 2002; KOPP et al., 2007; SCHMIDT et al., 2007) têm indicado como nível crítico de toxidez a concentração dos ácidos capaz de reduzir em 50\% o crescimento do sistema radicular. A redução do crescimento radicular é considerada a variável mais responsiva à toxidez por ácidos orgânicos, sendo utilizada em trabalhos de tolerância varietal para esse caráter (KOPP et al., 2007).

As concentrações de ácido acético necessárias para reduzir o crescimento do sistema radicular em $50 \%$ foram 2,7mM, para o milho e o sorgo, e $2 \mathrm{mM}$, para a soja (Figura 1a). No entanto, concentrações de ácido acético de 1,0mM foram suficientes para reduzir o comprimento radicular da soja em aproximadamente $30 \%$, e do milho e do sorgo em aproximadamente 15\%. Esses valores indicam que o milho e o sorgo apresentariam tolerâncias semelhantes e seriam mais tolerantes do que a soja à toxidez por ácido acético. Porém, a generalização de que uma espécie é mais tolerante do que outra pode incorrer em erros, pois existem diferenças na sensibilidade aos ácidos entre diferentes cultivares de uma mesma espécie. Assim, cultivares de soja melhor adaptadas a solos de várzea poderiam ser mais tolerantes a ácidos orgânicos do que cultivares de milho e sorgo menos adaptadas, embora isso não tenha sido ainda comprovado, necessitando, portanto, de estudos futuros. 


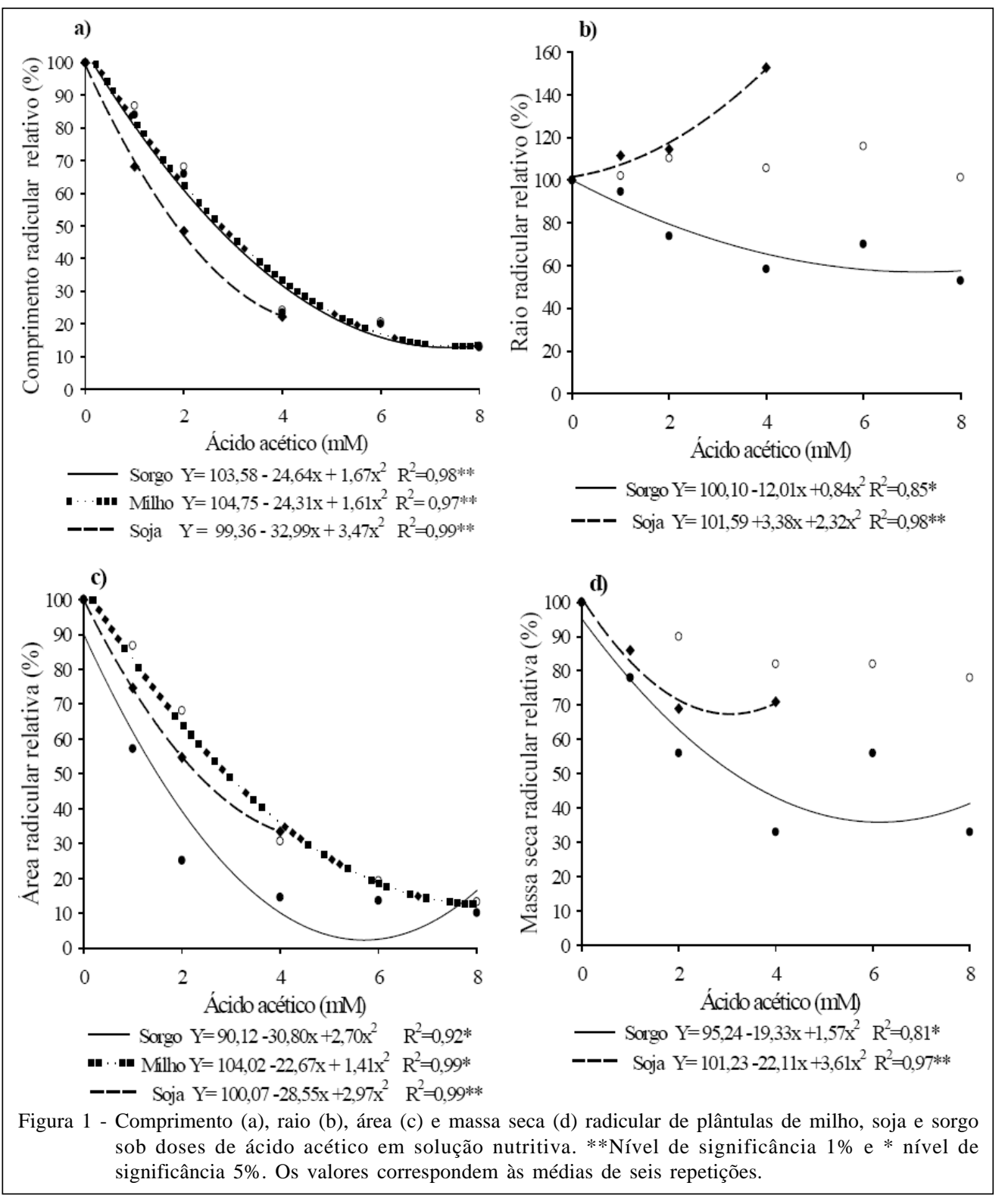

Para a variável raio radicular relativo, também foi verificada uma resposta diferencial ao ácido acético entre as culturas testadas (Figura 1b). Na presença do ácido acético, o raio radicular relativo da soja aumentou, enquanto que, no milho, o ácido não afetou significativamente essa variável. No entanto, para o sorgo, o acréscimo das concentrações de ácido acético ocasionou reduções no raio radicular, atingindo uma inibição de 50\% na concentração de 8,0mM. O aumento do raio radicular e a redução no crescimento da raiz são sintomas característicos da toxidez por ácidos orgânicos, tendo sido relatados em diversos trabalhos relacionados ao assunto (SOUSA \& BORTOLON, 2002; SOUSA et al., 2002; CAMARGO et al., 2001; KOPP et al., 2007). O aumento do raio radicular relativo na cultura da soja se relaciona ao fato de que, sob condições de estresse causado por ácidos orgânicos, as plantas apresentam um menor crescimento das raízes adventícias e um aumento da emissão de raízes laterais, mais curtas e grossas. CAMARGO et al. (2001) e ARMSTRONG \& ARMSTRONG (2001) observaram que as raízes adventícias diminuíam o seu crescimento, promovendo a proliferação de calos na base do coleóptilo e aumentando o número de raízes laterais, 
sendo esta a provável causa do aumento do número de raízes em arroz quando submetido a tratamentos com os ácidos acético, propiônico e butírico.

A massa seca da parte aérea das plântulas de milho, soja e sorgo diminuíram em presença de doses crescentes de ácido acético (Figura 2). A concentração de 8,0mM de ácido acético ocasionou reduções de 50 e $35 \%$ da massa seca relativa da parte aérea nas culturas do milho e do sorgo, respectivamente, enquanto que, para a massa seca relativa da soja, uma redução de $30 \%$ foi observada quando as plantas foram submetidas à concentração de $4,0 \mathrm{mM}$ de ácido acético. Particularmente em relação às plântulas de sorgo, observou-se que a massa seca relativa da parte aérea foi menos afetada pelo ácido acético do que a massa seca relativa radicular (Figura 1d e 2). Diversos autores (TAKIJIMA, 1964; RAO \& MIKKELSEN, 1977; CAMARGO et al., 1993) também observaram que a parte da planta que sofre os maiores efeitos de ácidos orgânicos é o sistema radicular. SOUSA \& BORTOLON (2002) observaram que uma inibição de 50\% no crescimento do sistema radicular de plantas de arroz foi obtida a uma concentração de $4,7 \mathrm{mM}$, enquanto que, na parte aérea, para atingir o mesmo valor de

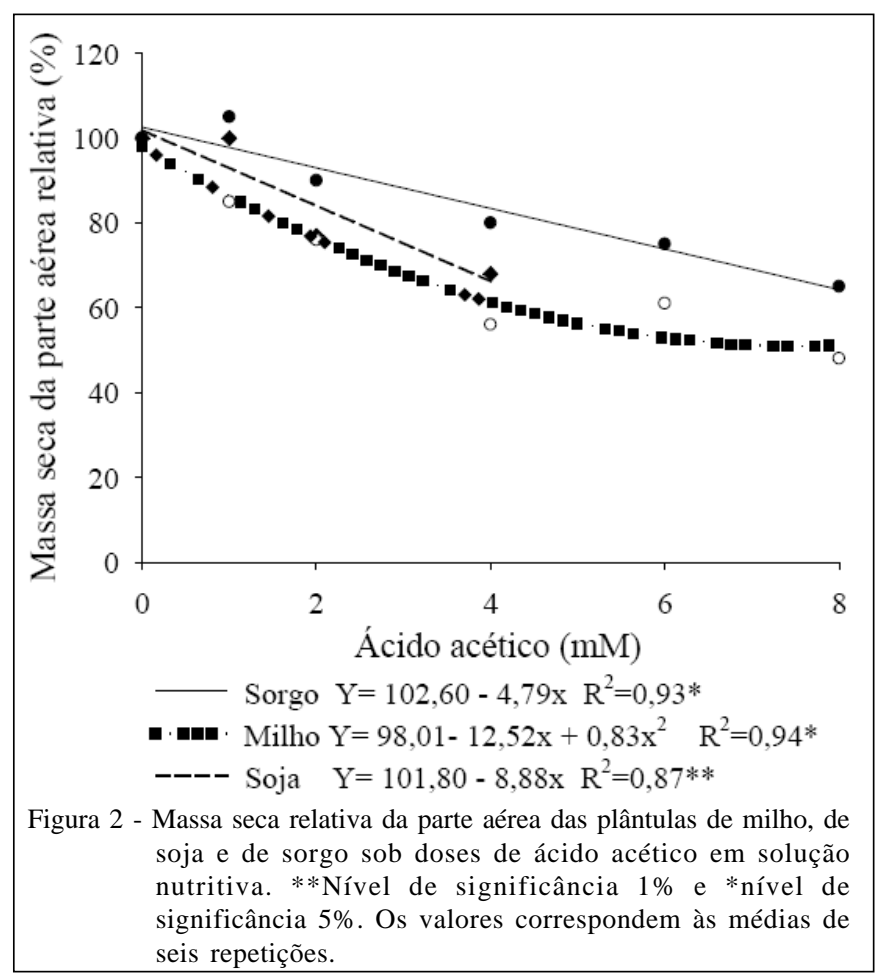

inibição, foi necessária uma concentração de 8,0mM de ácido acético.

As concentrações de nitrogênio, fósforo, potássio, cálcio e magnésio na parte aérea das plântulas foram afetadas pelo aumento das concentrações de ácido acético na solução nutritiva (Figuras 3a, b, c, d, e). Na soja, ocorreram reduções na concentração de fósforo, potássio, cálcio e magnésio; no milho, houve redução significativa da concentração de fósforo e magnésio e no sorgo ocorreram reduções nas concentrações de nitrogênio, potássio e magnésio na parte aérea. Diversos autores (TAKIJIMA, 1964; RAO \& MIKKELSEN, 1977; SOUSA \& BORTOLON, 2002) também observaram inibição na absorção de nutrientes como efeito dos ácidos orgânicos. De acordo com o descrito por LEE (1977), há duas possibilidades para a inibição da absorção de nutrientes em plantas sob o efeito de ácidos orgânicos. A primeira possibilidade se refere à capacidade dos ácidos orgânicos, outros ácidos tóxicos ou substâncias não polares de dissolver a camada lipídica da membrana celular, rompendo sua estrutura e facilitando o movimento de íons para fora da membrana. A segunda possibilidade se refere às mudanças que ocorrem no citoplasma ou no vacúolo celular das plantas quando da presença de um ácido fraco com $\mathrm{pH}$ menor que o do citoplasma (aproximadamente 7,0), havendo tendência deste entrar para dentro da célula. Dessa forma, o decréscimo do $\mathrm{pH}$ do vacúolo e do citoplasma inibe a absorção e a retenção normal de íons pela célula, causando perdas de solutos do tecido radicular das plantas.

\section{CONCLUSÃO}

O crescimento da parte aérea e do sistema radicular do milho, da soja e do sorgo diminui com a aplicação de doses crescentes de ácido acético em solução nutritiva até as doses de $8 \mathrm{mM}$, para sorgo e milho, e $4 \mathrm{mM}$, para soja. Os níveis críticos de toxidez do ácido acético capazes de causar inibição de 50\% do comprimento radicular são $2 \mathrm{mM}$, para a soja, e 2,7mM, para o milho e o sorgo.

Ciência Rural, v.40, n.5, mai, 2010. 


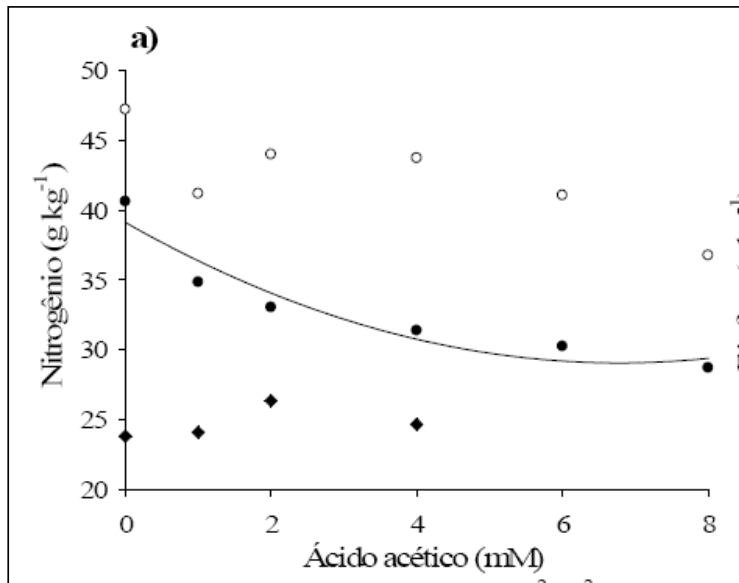

Sorgo $Y=39,13-2,97 x+0,22 x^{2} \quad R^{2}=0,92^{* * *}$

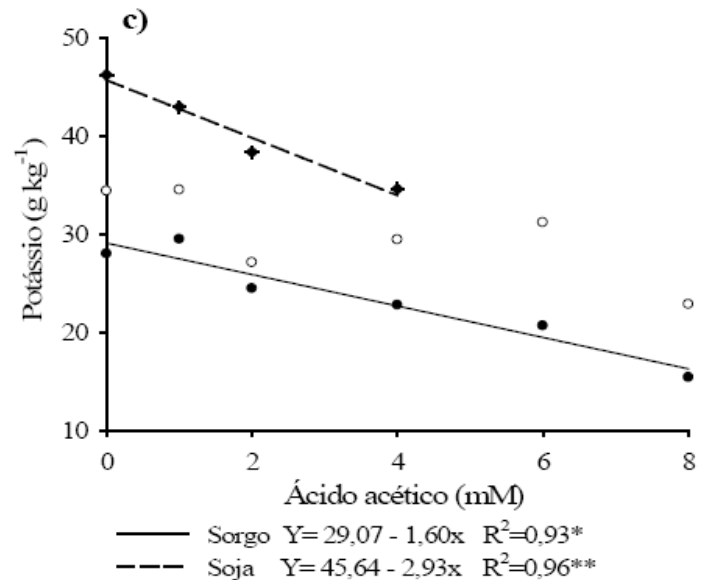

b)
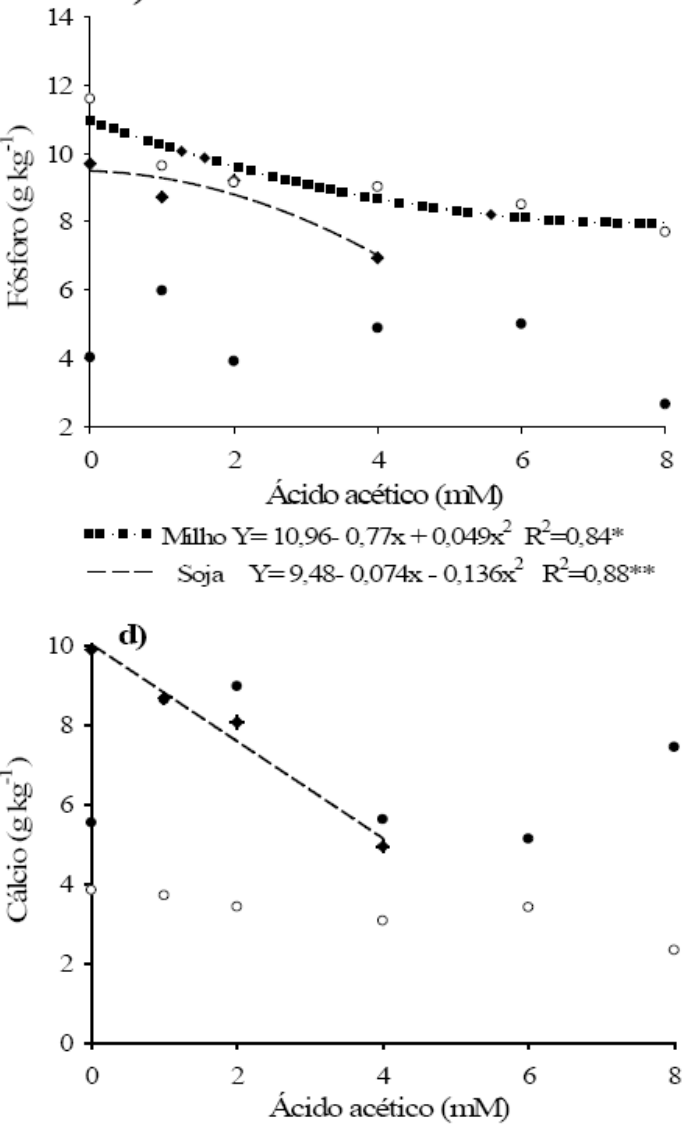

Soja $\mathrm{Y}=10,03-1,22 \mathrm{x} \quad \mathrm{R}^{2}=0,98^{* * *}$

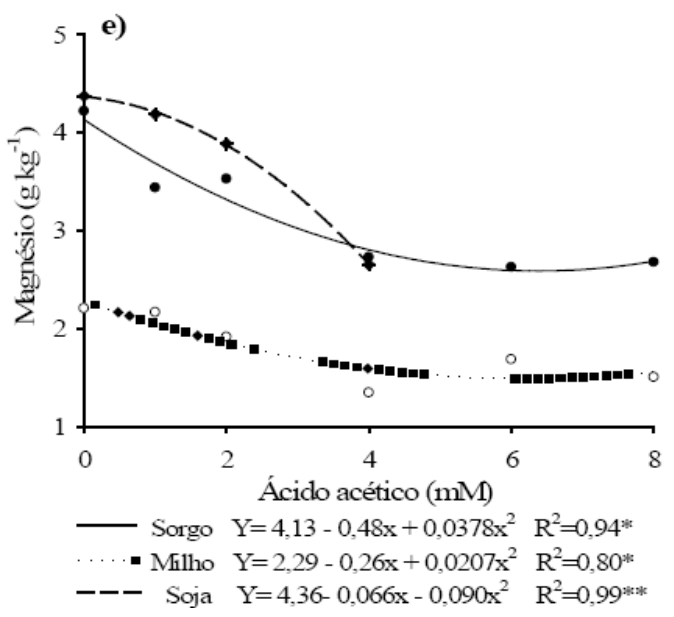

Figura 3 - Concentração de N, P, K, Ca e Mg na parte aérea das plântulas de milho, soja e sorgo, em funções de doses de ácido acético na solução nutritiva. **Nível de significância $1 \%$ e * nível de significância $5 \%$. Os valores correspondem às médias de seis repetições.

\section{REFERÊNCIAS}

ARMSTRONG, J.; ARMSTRONG, W. Rice and phragmites: effects of organic acids on growth, root permeability, and radial oxygen loss to the rhizosphere. American Journal of Botany, v.88, n.8, p.1359-1370, 2001. Disponível em: <http:// www.amjbot.org/cgi/content/full/88/8/1359>. Acesso em: 28 mai. 2009.

Ciência Rural, v.40, n.5, mai, 2010. 
BOHNEN, H. et al. Ácidos orgânicos na solução de um gleissolo sob diferentes sistemas de cultivo com arroz irrigado. Revista Brasileira de Ciência do Solo, v.29, n.3, p.475-480, 2005. Disponível em: <http://www.scielo.br/pdf/rbcs/v29n3/25748.pdf>. Acesso em: 18 ago. 2008.

CAMARGO, F.A. et al. Efeito dos ácidos acético e butírico sobre o crescimento de plântulas de arroz. Pesquisa Agropecuária Brasileira, v.28, n.9, p.1011-1018, 1993.

CAMARGO, F.A. de O. et al. Aspectos fisiológicos e caracterização da toxidez de ácidos orgânicos voláteis em plantas. Ciência Rural, v.31, n.3, p.523-529, 2001. Disponível em: <http://www.scielo.br/pdf/cr/v31n3/a29v31n3.pdf>. Acesso em: 3 ago. 2009.

JACKSON, P.C.; JOHN, J.B. Changes in membrane lipids of roots associated with changes in permeability: 1 . Effects of undissociated organic acids. Plant Physiology, v.66, p.801-804, 1980.

JONES, H.G.; JONES, M.B. Introduction: some terminology and commom mechanisms. In: JONES, H.G. et al. (Eds.). Plants under stress. Cambridge: Cambridge University, 1992. p.1-10.

LEE, R.B. Effects of organic acids on the loss of ions from barley roots. Journal of Experimental Botany, v.28. p.578587, 1977. Disponível em: <http://www.scielo.br/scieloOrg/php/ reflinks.php?refpid=S01038478200100030002900024\&pid=S0103847820010003>. Acesso em: 3 ago. 2009.

KROGMEIER, M.J.; BREMNER, J.M. Effects of aliphatic acids on seed germination and seedling growth in soil. Communications in Soil Science and Plant Analysis, v.21, n.7, p.547-555, 1990.

KOPP, M.M. et al. Níveis críticos dos ácidos acético, propiônico e butírico para estudos de toxicidade em arroz em solução nutritiva. Acta Botanica Brasílica, v.21. n.1, p.147-154, 2007. Disponível em: <http://www.scielo.br/pdf/abb/v21n1/14.pdf>. Acesso em: 3 ago. 2009.

LYNCH, J.M. Biotecnologia do solo - Fatores microbiológicos na produtividade agrícola. São Paulo: Manole, 1986. 209p.
PINTO, L.F.E. et al. Solos de várzea no sul do Brasil. In: GOMES, A.S.; MAGALHÃES Jr., A.M. (Eds.). Arroz irrigado no Sul do Brasil. Brasília: Embrapa-Informação Tecnológica, 2004. p.75-95.

RAO, D.N.; MIKKELSEN, D.S. Effect of acetic, propionic, and butyric acids on young rice seedlings growth. Agronomy Journal, v.69, n.6, p.923-928, 1977.

SAS Institute. SAS OnlineDoc ${ }^{\circledR}$ 9.1.2. JMP Statistics and Graphics Guide, version 5. Cary, NC, 2004. 1218p.

SCHMIDT, F. et al. Toxidez pelos ácidos propiônico e butírico em plântulas de arroz. Ciência Rural, v.37, n.3, p.720-726, 2007. Disponível em: <http://www.scielo.br/pdf/cr/v37n3/ a18v37n3.pdf $>$. Acesso em: 18 ago. 2009.

SOUSA, R.O.; BORTOLON, L. Crescimento radicular e da parte aérea do arroz (Oryza sativa L.) e absorção de nutrientes, em solução nutritiva com diferentes concentrações de ácido acético. Revista Brasileira de Agrociência, v.8, n.3, p.231235, 2002.

SOUSA, R.O. et al. Short chain organic acids dinamics in solution of flooded soil treated with ryegrass residues. Communications in Soil Science and Plant, v.33, n.5-6, p.779-787, 2002. Disponível em: $<$ h t t p : / / w w w. in forma world.com/s m p p/ content $\sim$ content $=\mathrm{a} 713623850 \sim \mathrm{db}=$ All $\sim$ order=page $>$. Acesso em: 05 mai. 2009. doi: 10.1081/CSS-120003065.

TAKENAGA, H. Nutrient absorption in relation to environmental factors. In: MATSUO, T. et al. Science of the rice plant: physiology. Tokyo: Nosan Gyoson Bunka Kyokai, 1995. p.278-294.

TAKIJIMA, Y. Growth inhibiting action of organic acids and absorption and decomposition of them by soils. Soil Science Plant Nutrition, v.10, n.5, p.204-211, 1964.

TEDESCO, M.J. et al. Análise de solo, plantas e outros materiais. 2.ed. Revisada e ampliada. Porto Alegre: Departamento de Solos da UFRGS, 1995. 174p.

TENNANT, A. A test of modified line intersect method of estimating root lenght. Journal Applied Ecology, v.63, n.6, p.995-1001, 1975. 